\title{
The Effects of 12 Weeks Pilates Exercises on Functional and Cognitive Performance in Elderly People
}

\author{
Buket Kayaoğlu ${ }^{1}$, İlbilge Özsu \\ ${ }^{1}$ Healt Sciences Institute, Uşak University, Uşak, Turkey \\ ${ }^{2}$ Faculty of Sports Sciences, Uşak University, Uşak, Turkey \\ Correspondence: Buket Kayaoğlu, Healt Sciences Institute, Uşak University, Uşak, Turkey
}

Received: February 20, 2019

Accepted: February 28, 2019 Online Published: March 6, 2019

doi:10.11114/jets.v7i3S.4123

URL: https://doi.org/10.11114/jets.v7i3S.4123

\begin{abstract}
The aim of the study was to investigate the effects of 12 weeks Pilates exercises on functional and cognitive performance in elderly people which are living in an elderly care center. Forty three elderly were randomly allocated either to Pilates group (PG, $\mathrm{n}=21$; mean age, $72.8 \pm 7.84$ years), which performed three session of Pilates per week for 12 weeks, or to control group ( $\mathrm{CG}, \mathrm{n}=22$; mean age, $77.7 \pm 7.25$ years), which no performed any exercise is except from daily works. Participants tested to handgrip strength, Berg balance scale, Functional reach test and Mini Mental State Examination Test before and after the 12 weeks of exercise. Finally, PG demonstrated improvement in all variables. However, CG has no improvement any variables. Pilates exercises led to significant improvement in functional and cognitive performance. Therefore, elderly people can apply a well-structured Pilates exercise program under Pilates instructor and physiotherapist.
\end{abstract}

Keywords: elderly, pilates, mini mental state examination, berg Scale, functional reach test

\section{Introduction}

Elderliness is a period which is required by evaluation with physical, psychological and social dimensions. Physiological elderliness can be defined changes which were occurred with chronological age (Beğer and Yavuzer, 2012). Conventionally, "elderly" has been defined as a chronological age of 65 years old or older, while those from 65 through 74 years old are referred to as "early elderly" and those over 75 years old as "late elderly" (Orimo et al.,2006).

A report which was released by World Health Organization (WHO) informed that in 2010, an estimated 524 million people were aged 65 or older. This ratios are equal to $8 \%$ world's population. By 2050 , this number expected to nearly triple to about 1.5 billion, representing $16 \%$ of the world's population

(https://www.who.int/ageing/publications/global_health.pdf?ua=1).

Elderliness has considerable health problem and function loss such as hearing loss, visual and vestibular function impairment, urologic changes, cardiovascular diseases, osteoarthritis, osteoporosis, diabetes mellitus, dementia, depression and even cancer (Jaul and Barron, 2017).

Physical function impairments are characterized by decline walking speed, loss of skeletal muscles mass (sarcopenia), frailty, impairment balance and falls are effects of daily life quality and life expectancy in in elderliness (Jaul and Barron,2017).

Peel (2011) reported that falls among people aged 65 years and older are leading cause of fatal and non-fatal unintentional injuries accounting for $40 \%$ of all injury- related deaths.

A position stand released by American College of Sport Medicine (ACSM) argued that although no physical activity can stop the biological aging process, however regular physical activity can minimize physical, physiological and functional impairment (Chodzko-Zajko et al., 2009). This position stand also suggested that exercise prescription for older adults should include aerobic exercise, muscle strengthening exercises, and flexibility exercises. In addition, individuals who are at risk for falling or mobility impairment should also perform specific exercises to improve balance in addition to the other components of health-related physical Fitness (Chodzko-Zajko et al, 2009).

Muscle strengthening activity and balance exercise three times each week was effective in fall prevention (Nelson et al., 
2007). Pilates has recently gained in popularity and seems to be an efficient manner of strengthening the muscles of the trunk (core training), postural balance, and aspects of quality of life (de Oliveira et al., 2015). A review showed that Pilates exercises might be considered an exercise intervention that is capable to increase muscle strength as well as to improve static and dynamic balance in elderly populations. Furthermore, functional capacity to perform daily living activities and quality of life can be generally improved if elderly engage in Pilates exercises (Bullo et al., 2015). Therefore, this study is aimed to investigate the effect of 12 weeks Pilates exercises on functional and cognitive performance in elderly people which are living in an elderly care center.

\section{Method}

\section{The Study Group}

Forty-three individuals aged over 65 years living in an elderly care center participated as volunteers. The participants were randomly divided into two groups as Pilates $(n=21,10$ male +11 female $)$ and control $(n=22,15$ male +7 female) groups. The ethics committee approval of the study was obtained from Uşak University Health Sciences Scientific Research and Publication Ethics Committee (approval number: 2017-45). Participants were informed about the study and received written consent. The descriptive characteristics of the participants are shown in Table 1.

Table 1. The descriptive characteristics of the participants

\begin{tabular}{lccc}
\hline & \multicolumn{2}{c}{ Mean \pm SD } & p \\
\hline & Control Group $(\mathrm{CG})$ & Pilates Group $(\mathrm{PG})$ & \\
& $(\mathrm{n}=21)$ & \\
\hline Age (year) & $77.7 \pm 7.25$ & $72.8 \pm 7.84$ & $0.039^{*}$ \\
Mass (kg) & $69.9 \pm 15.8$ & $72.9 \pm 13.6$ & 0.498 \\
Height (cm) & $155 \pm 11.2$ & $162 \pm 7.61$ & $0.031^{*}$ \\
\hline
\end{tabular}

SD: Standard deviation.

$\mathrm{p}<0.05$

Participation criteria of participants; to be in a group in which the physiotherapists and doctors in the elderly care center allow them to participate in the regular exercise group, not to have neurophysiological, physiological and physical disorders that may cause obstacles to regular exercise, to read and sign the informed volunteer consent form which declare that volunteer to participate in the study.

Exclusion criteria of participants; not to be in a group in which the physiotherapists and doctors in the elderly care center allow them to participate in the regular exercise group, to have neurophysiological, physiological and physical disorders that may cause obstacles to regular exercise, not to participate for more than 2 weeks of the 12-week exercise period, the emergence of new disturbances that will be a drawback or obstacle to exercise during exercise period, to refuse to participate voluntarily, not to read and sign the informed volunteer consent form even if declare that volunteer to participate in the study.

\section{Research protocol}

For the purpose of our study, the participants were evaluated at the beginning of the study and after 12 weeks in terms of Mini Mental State Examination Test, Berg balance test, functional reach test, and hand-grip strength.

Pilates exercises were applied to the experimental group between 10: 00-11: 00 for 12 weeks and 3 days/60 minutes. 1 hour exercise started with 10 minutes breathing techniques followed by 10 minutes warming, 30 minutes basic Pilates movements (4 repetitions in the first 4 weeks, 8 repetitions in the second month, 12 repetitions in the last month ( 2 sets in bilateral movements, 1 set in unilateral movements) and finally 10 minutes relaxation and cooling exercises were applied. Pilates exercises consisted of spine stretch, hundred, spine twist supine, roll up, neck pull, saw, one leg stretch (single-leg stretch), scissors, bicycle, control balance, one leg circle, leg pull front and side bend. The control group did not participate in any structured activity for 12 weeks and continued its daily activities. The research protocol is shown in Figure 1. 


\begin{tabular}{|ccc|}
\hline PRE TEST & TREATMENTS & POST TEST \\
Berg Balance Scale & Control Group & \\
Hand-Grip Strength Test & $(\mathrm{N}=22)$ & \\
Functional Reach Test Mini & Individual Daily Works & Berg Balance Scale \\
Mental State Examination Test & Exercise Group & Hand-Grip Strength Test \\
& $(\mathrm{N}=21)$ & Functional Reach Test Mini \\
& Individual Daily Works & Mental State Examination Test \\
& + & \\
& & \\
& & \\
& & \\
\end{tabular}

Figure 1. Flowchart of the study

\section{Measurement Instruments and Test Protocols}

1. Handgrip Strength Test: Grip strength measured by using an adjustable digital handgrip dynamometer (Takei Scientific Instruments Co., Ltd., Japan). If there were no paralysis, unconsciousness or other conditions in the participants, measurements were taken from the active side. While standing, elbow joint stretched, arm-body abduction angle of 45 degrees without any support from anywhere, the participant was required to grasp the digital handgrip dynamometer with his fingers and applied 5-6 seconds of force. The application was performed 3 repetitions with rest intervals. 3 values were written to the forms and the highest value was taken into consideration. During the application of the test, an expert stayed on both sides of the participant in case of the risk of falling.

2. Functional Reach Test (FR): Dynamic balance of the subjects was evaluated by Functional Reach Test in this study. The test used for only forward position in this study. Duncan et al (1990) reported that FR test has high reliability and validity for adults aged $20-87$ years. The ability of standing subjects to reach with the left hand horizontally forward (90 degrees shoulder flexion and straight arm) while maintaining a fixed base of support was examined. Instructions were similar to those of Duncan et al. (1990). A 150-cm yardstick was horizontally mounted on the wall, at the height of the acromion. Reach distance was measured as the displacement of the finger between initial position and end position. Asked to the subject reach forward as far as without taking a step and keeping your hands in a fist shape. Results were recorded as $\mathrm{cm}$. During the application of the test, an expert stayed on both sides of the participant in case of the risk of falling.

3. Berg Balance Scale (BBS): Risk of falling of the subjects in this study was evaluated by Berg Balance test. The Berg Balance Scale (BBS) was originally developed for the assessment of postural control, and is widely used in many fields of rehabilitation (Berg et al., 1992). According to Şahin et al (2008) The Turkish version of the BBS is a reliable and valid scale to be used in balance assessment of Turkish older adults. The aim of this test is to gain knowledge about the participants' postural control, balance ability and awareness level. The Berg balance scale consists of 14 items evaluating daily activities. and each item is rated between 0-4 points as static standing, standing static posture, standing balance transfers, rotation, step against the step test, taking an object from the ground, return to the old position, the transition from ambulatory position, from sitting position to bed. It consists of items that evaluate daily activities such as transfers. Berg's balance test has a score evaluation based on whether the participant can perform independently and safely. The total score was 56 points and the participants were evaluated by this score. Berg's balance test was carried out with at least two experts in order to prevent the negative positions such as falling.

4. Mini Mental State Examination Test (MMSE): Cognitive function of the subjects was evaluated by MMSE. Güngen et al (2002) reported that the Turkish version of the MMSE has high reliability and validity for the diagnosis of mild dementia in Turkish. The aim of this test is to obtain information on the level of cognitive functioning of the participants. The Mini Mental State Examination Test is a short, useful and standardized material that can be used to determine the cognitive level and its application in the elderly. The Standardized Mini Mental Test consists of 11 items which are grouped under 5 main headings: orientation, recording memory, attention and calculation, recall and language. In the light of the literature information, those who are literate were evaluated over 30 points and the scores of illiterate were evaluated over 24 points. During the cognitive function test, the participants were taken to the room one by one to avoid being affected each other. Each participant was measured in the same room under the same conditions and both pre-test and post-test were performed in the same place. 


\section{Statistics}

Study data were analyzed using the SPSS $^{\circledR}$ Statistics for Windows version 20 software program (IBM, Armonk, NY; 2011). To assess the normality of residuals of related data, the Shapiro-Wilk test was performed and skewness and kurtosis values were checked. Time (pre-test, post-test) was the within subject factor and Group (Pilates, Control) was the between subject factor of the current study. Interaction effects of factors on performance variables were investigated using mixed design analysis of variance (ANOVA; $2 \times 2$, Group $\times$ Time). Performance changes were compared between groups using independent samples t-test. Levene's test was used to check for the equality of error variances assumption. Unbiased effect sizes of the differences (Hedge's $\mathrm{d}$; $\mathrm{d}<0.2$ trivial, $0.2 \leq \mathrm{d}<0.5$ small, $0.5 \leq \mathrm{d} \leq 0.8$ moderate, $\mathrm{d}>0.8$ large effect size) were also reported. Statistical significance level was set at $\mathrm{p} \leq 0.05$ for all analyses.

\section{Findings}

According to $2 \times 2$ (Group $\times$ Time) mixed design ANOVA results, there were statistically significant interaction effects between Group and Time regarding all the performance variables indicating that all performance variables showed different change patterns between groups across 12 -week training period (mini mental state exam.: $F[1,41]=28.6, p<$ $0.001, \mathrm{\eta}_{\mathrm{p}}{ }^{2}=0.41$; Functional reach: $\mathrm{F}[1,41]=17.5, \mathrm{p}<0.001, \mathrm{\eta}_{\mathrm{p}}{ }^{2}=0.30$; Berg balance: $\mathrm{F}[1,41]=30.1, \mathrm{p}<0.001, \mathrm{\eta}_{\mathrm{p}}{ }^{2}$ $=0.42$; handgrip strength: $\left.\mathrm{F}[1,41]=7.83, \mathrm{p}=0.008, \mathrm{\eta}_{\mathrm{p}}{ }^{2}=0.16\right)$. Improvements in these performance variables were significantly higher in Pilates group when compared to control group (Table 1).

Table 1. Comparison of performance changes between Pilates and Control groups

\begin{tabular}{|c|c|c|c|c|c|c|c|}
\hline & Group & Time & Score & $\begin{array}{c}\% \Delta \\
\text { Mean } \pm \text { SD }\end{array}$ & $\begin{array}{c}\text { Difference } \\
\text { in } \% \Delta \\
\text { Mean } \pm \text { SE }\end{array}$ & $\mathrm{p}$ & d \\
\hline \multirow{2}{*}{$\begin{array}{l}\text { Mini Mental } \\
\text { State Exam. }\end{array}$} & Pilates & $\begin{array}{l}\text { Pre-test } \\
\text { Post-test }\end{array}$ & $\begin{array}{l}20.0 \pm 4.6 \\
23.2 \pm 4.8\end{array}$ & $17.0 \pm 11.8$ & \multirow{2}{*}{$23.7 \pm 4.4$} & \multirow{2}{*}{$<0.001 *$} & \multirow{2}{*}{1.10} \\
\hline & Control & $\begin{array}{l}\text { Pre-test } \\
\text { Post-test }\end{array}$ & $\begin{array}{l}22.6 \pm 5.8 \\
21.2 \pm 6.0\end{array}$ & $-6.64 \pm 17.0$ & & & \\
\hline \multirow{2}{*}{$\begin{array}{c}\text { Functional } \\
\text { Reach }\end{array}$} & Pilates & $\begin{array}{l}\text { Pre-test } \\
\text { Post-test }\end{array}$ & $\begin{array}{l}18.5 \pm 6.6 \\
23.1 \pm 8.3 \\
\end{array}$ & $28.6 \pm 32.9$ & \multirow{2}{*}{$33.7 \pm 8.7$} & \multirow{2}{*}{$<0.001^{*}$} & \multirow{2}{*}{1.18} \\
\hline & Control & $\begin{array}{l}\text { Pre-test } \\
\text { Post-test }\end{array}$ & $\begin{array}{l}21.1 \pm 8.2 \\
19.9 \pm 8.2\end{array}$ & $-5.09 \pm 22.0$ & & & \\
\hline \multirow{2}{*}{ Berg Balance } & Pilates & $\begin{array}{l}\text { Pre-test } \\
\text { Post-test }\end{array}$ & $\begin{array}{l}45.6 \pm 8.0 \\
48.7 \pm 6.5 \\
\end{array}$ & $8.09 \pm 10.0$ & \multirow{2}{*}{$15.1 \pm 3.3$} & \multirow{2}{*}{$<0.001 *$} & \multirow{2}{*}{1.37} \\
\hline & Control & $\begin{array}{l}\text { Pre-test } \\
\text { Post-test }\end{array}$ & $\begin{array}{c}47.1 \pm 9.9 \\
44.7 \pm 11.8\end{array}$ & $-6.98 \pm 11.6$ & & & \\
\hline \multirow{2}{*}{ Hand Grip } & Pilates & $\begin{array}{l}\text { Pre-test } \\
\text { Post-test } \\
\end{array}$ & $\begin{array}{l}19.5 \pm 8.8 \\
22.4 \pm 9.7\end{array}$ & $16.6 \pm 20.2$ & \multirow{2}{*}{$18.6 \pm 5.4$} & \multirow{2}{*}{$0.001 *$} & \multirow{2}{*}{1.04} \\
\hline & Control & $\begin{array}{l}\text { Pre-test } \\
\text { Post-test }\end{array}$ & $\begin{array}{c}26.6 \pm 9.7 \\
26.6 \pm 10.8\end{array}$ & $-2.09 \pm 14.4$ & & & \\
\hline
\end{tabular}

\section{Discussion and Conclusion}

The aim of this study is to investigate the effect of Pilates exercises which treated 3 sessions per week for 12 weeks on functional (grip strength, functional reach, Berg balance test) and cognitive (mini mental state examination) performance in elderly people which are living in an elderly care center. The main finding of the study is Pilates exercises lead to significant improvement in hand grip strength, Functional reach and Berg balance tests score as well as mini mental state examination test results.

According to results of the current study, we concluded that improvement of functional reach and Berg balance score are attributable to strength enhancement in lower extremity muscles. However, we did not evaluate strength of the lower muscle, some researchers informed that grip strength a simple bedside tool, has been shown to be a valid surrogate measurement of overall muscular strength (Bohannon, 2001; Innes, 1999).

Boguszewski et al (2012) and Fernandez et al (2013) reported that Pilates exercises are not effective in improvement strength of upper limbs strength. However, as in our study, Fourie et al (2012) and Kovach et al (2013) reported that Pilates exercises are effective in increasing upper limbs strength.

Elderly people are related with fall risk, that is one of the major public health issue associated with substantial healthcare costs and risk for disability, hospitalization, even mortality (Patel et al., 2014 ). On the other hand, Garatachea and Lucia (2013) informed that physical activity which are including endurance, resistance, flexibility and balance exercise reduced fall risk and enhancement functional independence of the elder people.

de Oliveira et al (2015) reported that Pilates exercises two times weekly for 12 week lead significant improvement in 
postural balance and functional stability when examined by Berg Balance Scale and Timed Up and Go Test. On the other hand, Irez (2014) argued that both walking exercise and Pilates exercises improve Berg balance score and also Pilates exercise might be an alternative way of improving certain physical fitness parameters among the elderly.

In a study by Mokhtari et al (2012) shown that Pilates exercises, 3 sessions of one hour per week for a duration of 12 weeks, lead to significant improvement in dynamic balance when it measured by functional reach test. On the contrary to de Oliveira et al (2015), Irez (2014) and Mokhtari et al (2012), Gabizon et al (2016) argued that group Pilates exercises, 3 sessions of one hour per week for a duration of 36 training sessions over three months did not improve objective measures of balance control (berg balance scale, Tinetti assessment tool etc) or self-reported health status (SF-36) in older adults.

As we understand, there are studies reported conflicting results of the Pilates exercises on functional performance. These conflicting results might be caused by many factors such as total time, intensity and type of the Pilates exercises, baseline health and physical function capacity of the elderly, test equipment which used for measurement balance, strength etc.

Decrement cognitive functions, short-term memory loss, dementia and depression etc. are the important health issues among elderly (Jaul and Barron, 2017). ACSM reported that regular physical activity is associated with significant improvements in overall psychological health and well-being (Chodzko-Zajko et al., 2009). Mokhtari et al (2012) reported that Pilates exercises decreased depression by increasing blood serotonin level. Researchers informed that physical exercise such as strength training, combine exercises, tai chi as well as Pilates exercise is an effective non-pharmacological intervention to improve cognitive performance and quality of life in elderly (Tavares et al.,2014; Mariano et al.,2013; de Carvalho Bastone).

Our study has some limitations that should be mentioned at this point. One of the limitations, Pilates group were younger, taller and heavier than control group in terms of baseline descriptive characteristic.. Second limitation is, we did not evaluate some body composition such as muscle mass, body fat ratio etc. These limitations might be lead to misinterpretation the results.

Finally, Pilates exercises led to significant improvement in functional and cognitive performance in elderly. Therefore, elderly people can apply a well-structured Pilates exercises program under Pilates instructor and physiotherapist.

\section{Acknowledgement}

This study was produced from master's thesis of Buket Kayaoğlu and was funded by Uşak University BAP (2017/TP048). We would like to thank to Dr. Cem Kurt for his valuable contributions in the writing stage and to elderly care center employees and management to open their doors for collecting data.

\section{References}

Beğer, T., \& Yavuzer, H. (2012). Yaşlılık ve yaşlılık epidemiyolojisi. Klinik Gelişim, 25(3), 1-3.

Berg, K. O., Wood-Dauphinee, S. L., Williams, J. I., \& Maki, B. (1992). Measuring balance in the elderly: validation of an instrument. Canadian Journal of Public Health, 83, S7-11.

Boguszewski, D., Adamczyk, J., \& Ochal, A. (2012). The role of Pilates and aquafitness exercises in sustaining the health and fitness of elderly women. Sport Science Review, 21(3-4), 127-138. https://doi.org/10.2478/v10237-012-0013-7

Bohannon, R. W. (2001). Dynamometer measurements of hand-grip strength predict multiple outcomes. Perceptual and Motor Skills, 93(2), 323-328. https://doi.org/10.2466/pms.2001.93.2.323

Bullo, V., Bergamin, M., Gobbo, S., Sieverdes, J. C., Zaccaria, M., Neunhaeuserer, D., \& Ermolao, A. (2015). The effects of Pilates exercise training on physical fitness and wellbeing in the elderly: a systematic review for future exercise prescription. Preventive Medicine, 75, 1-11. https://doi.org/10.1016/j.ypmed.2015.03.002

Chodzko-Zajko, W. J., Proctor, D. N., Singh, M. A. F., Minson, C. T., Nigg, C. R., Salem, G. J., \& Skinner, J. S. (2009). Exercise and physical activity for older adults. Medicine \& Science in Sports \& Exercise, 41(7), 1510-1530. https://doi.org/10.1249/MSS.0b013e3181a0c95c

de Carvalho Bastone, A. (2004). Effect of an exercise program on functional performance of institutionalized elderly. Journal of Rehabilitation Research \& Development, 41(5). https://doi.org/10.1682/JRRD.2003.01.0014

de Oliveira, L. C., de Oliveira, R. G., \& de Almeida Pires-Oliveira, D. A. (2015). Effects of Pilates on muscle strength, postural balance and quality of life of older adults: a randomized, controlled, clinical trial. Journal of Physical Therapy Science, 27(3), 871-876. https://doi.org/10.1589/jpts.27.871

Duncan, P. W., Weiner, D. K., Chandler, J., \& Studenski, S. (1990). Functional reach: a new clinical measure of balance. Journal of Gerontology, 45(6), M192-M197. https://doi.org/10.1093/geronj/45.6.M192

Fernández Roldán, K., Benítez Jiménez, A. (2013). Influencia de la práctica del método pilates sobre la sarcopenia. 
Kronos, 8 (1), 51-55.

Fourie, M., Gildenhuys, G. M., Shaw, I., Shaw, B. S., Toriola, A. L., \& Goon, D. T. (2012). Effects of a mat Pilates programme on muscular strength and endurance in elderly women: exercise physiology. African Journal for Physical Health Education, Recreation and Dance, 18(2), 299-307.

Gabizon, H., Press, Y., Volkov, I., \& Melzer, I. (2016). The effects of pilates training on balance control and self-reported health status in community-dwelling older adults: a randomized controlled trial. Journal of Aging and Physical Activity, 24(3), 376-383. https://doi.org/10.1123/japa.2014-0298

Garatachea, N., \& Lucia, A. (2013). Genes, physical fitness and ageing. Ageing Research Reviews, 12(1), 90-102. https://doi.org/10.1016/j.arr.2012.09.003

Güngen, C., Ertan, T., Eker, E., Yaşar, R., \& Engin, F. (2002). Standardize mini mental test'in Türk toplumunda hafif demans tanısında geçerlik ve güvenilirliği. Türk Psikiyatri Dergisi, 13(4), 273-281.

https://www.who.int/ageing/publications/global_health.pdf?ua=1

Innes, E. V. (1999). Handgrip strength testing: a review of the literature. Australian Occupational Therapy Journal, 46(3), 120-140. https://doi.org/10.1046/j.1440-1630.1999.00182.x

Irez, G. B. (2014). The effects of different exercises on balance, fear and risk of falling among adults aged 65 and over. The Anthropologist, 18(1), 129-134. https://doi.org/10.1080/09720073.2014.11891528

Jaul, E., \& Barron, J. (2017). Age-related diseases and clinical and public health implications for the 85 years old and over population. Frontiers in Public Health, 5, 335. https://doi.org/10.3389/fpubh.2017.00335

Kovách, M. V., Plachy, J. K., Bognár, J., Balogh, Z. O., \& Barthalos, I. (2013). Effects of Pilates and aqua fitness training on older adults' physical functioning and quality of life. Biomedical Human Kinetics, 5(1), $22-27$. https://doi.org/10.2478/bhk-2013-0005

Mariano, E. R., Navarro, F., Sauaia, B. A., Junior, O., \& Marques, R. F. (2013). Muscular strength and quality of life in elderly women. Revista Brasileira de Geriatria e Gerontologia, 16(4), 805-811. https://doi.org/10.1590/S1809-98232013000400014

Mokhtari, M., Nezakatalhossaini, M., \& Esfarjani, F. (2013). The effect of 12-week pilates exercises on depression and balance associated with falling in the elderly. Procedia-Social and Behavioral Sciences, 70, 1714-1723. https://doi.org/10.1016/j.sbspro.2013.01.246

Nelson, M. E., Rejeski, W. J., Blair, S. N., Duncan, P. W., Judge, J. O., King, A. C., ... \& Castaneda-Sceppa, C. (2007). Physical activity and public health in older adults: recommendation from the American College of Sports Medicine and the American Heart Association. Circulation, 116(9), 1094.

https://doi.org/10.1161/CIRCULATIONAHA.107.185650

Orimo, H., Ito, H., Suzuki, T., Araki, A., Hosoi, T., \& Sawabe, M. (2006). Reviewing the definition of “elderly". Geriatrics \& Gerontology International, 6(3), 149-158. https://doi.org/10.1111/j.1447-0594.2006.00341.x

Patel, K. V., Phelan, E. A., Leveille, S. G., Lamb, S. E., Missikpode, C., Wallace, R. B., ... \& Turk, D. C. (2014). High prevalence of falls, fear of falling, and impaired balance in older adults with pain in the United States: findings from the 2011 National Health and Aging Trends Study. Journal of the American Geriatrics Society, 62(10), 1844-1852. https://doi.org/10.1111/jgs.13072

Peel, N. M. (2011). Epidemiology of falls in older age. Canadian Journal o Aging/La Revue Canadienne du Vieillissement, 30(1), 7-19. https://doi.org/10.1017/S071498081000070X

Sahin, F., Yilmaz, F., Ozmaden, A., Kotevoglu, N., Sahin, T., \& Kuran, B. (2008). Reliability and validity of the Turkish version of the Berg Balance Scale. Journal of Geriatric Physical Therapy, 31(1), 32-37. https://doi.org/10.1519/00139143-200831010-00006

Tavares, B. B., Moraes, H., Deslandes, A. C., \& Laks, J. (2014). Impact of physical exercise on quality of life of older adults with depression or Alzheimer's disease: a systematic review. Trends in Psychiatry and Psychotherapy, 36(3), 134-139. https://doi.org/10.1590/2237-6089-2013-0064

\section{Copyrights}

Copyright for this article is retained by the author(s), with first publication rights granted to the journal.

This is an open-access article distributed under the terms and conditions of the Creative Commons Attribution license which permits unrestricted use, distribution, and reproduction in any medium, provided the original work is properly cited. 